\title{
A MALDIÇÃO DE CHRONOS E A EDUCAÇÃO REMOTA EM TEMPOS DE PANDEMIA DA COVID-19
}

\author{
CHRONOS'S CURSE AND REMOTE EDUCATION IN COVID-19 PANDEMIC TIMES
}

\author{
Alex Sander da Silva ${ }^{1}$ \\ Marta Regina Furlan de Oliveira ${ }^{2}$ \\ Nilo Agostini ${ }^{3}$
}

\section{http://dx.doi.org/10.52641/cadcaj.v6i4.525}

\begin{abstract}
RESUMO: A metáfora da maldição de Chronos na mitologia grega congrega com a educação remota em tempos de pandemia da Covid-19. Diante disso, este ensaio teórico, objetiva desenvolver uma releitura reflexiva desses temas que se inter-relacionam, cujo fio condutor será uma reinterpretação adorniana da educação contra a barbárie, ou parafraseando, Adorno, da Educação após Auschwtiž por Educação após pandemia como contraponto de um tempo de desesperança. Também e não menos preocupante é o tempo do trabalho remoto, tempos do home office. A maioria das pessoas estão em casa aparentemente com muito tempo e, ao mesmo tempo, com pouco tempo. Isso leva a entender sobre um tempo de paradoxos do tempo. Em certo aspecto, o tempo desacelerou, as cidades pararam, o tempo da educação se modificou e vem se metamorfosiano. Isto nos leva a abordar igualmente o kairós que, em Benjamin, suscita a força messiânica do ser humano na luta pela libertação, alimentando os estilhaços de esperança que, segundo Freire, serão adubados pela confiabilidade numa revolução criadora de vida.
\end{abstract}

Palavras-chaves: Educação. Chronos. Ensino Remoto.

ABSTRACT: The metaphor of the Chronos malison in Greek mythology combines with remote education in times of Covid-19 pandemic. Therefore, this theoretical essay seeks to develop a reflexive reinterpretation of these interrelated themes, whose guiding thread will be an Adornian reinterpretation of education against barbarism, or paraphrasing, Adorno, in "Education after Auschwtiz", for "Education after pandemic" as a counterpoint to a time of hopelessness. Also, no less worrying is the time of remote work, times of home office. Most people are at home apparently with a lot of time and, at the same time, with little time. This leads to understand about a time of time paradoxes. In a certain way, time has slowed down, cities have stopped, education time has changed and has been changing. This leads us to also address the kairós that, in Benjamin, arouse the messianic strength of the human being in the struggle for liberation,

\footnotetext{
${ }^{1}$ Pós doutor em Educação pela Universidade Metododista de Pircacicaba (UNIMEP). Doutor em Educação pela Pontificia Universidade Catolica do Rio Grande do Sul (PUCRS). Docente do Programa de Pós-Graduação em Educação da Universidade do Extremo Sul Catarinense- (UNESC). Lattes: http://lattes.cnpq.br/285051408370454. ORCID: https://orcid.org/0000-0002-0945-9075 E-mail: alexsanders@,unesc.net

2 Pós doutora em Educação pela Universidade Estadual Paulista Júlio de Mesquita Filho. Doutora em Educação pela Universidade Estadual de Maringá (UEM). Docente do Departamento de Educação e do Programa de PósGraduação em Educação da Universidade Estadual de Londrina (UEL). Lattes: http://lattes.cnpq.br/8423465824507075. ORCID: $\quad$ http://orcid.org/0000-0003-2146-2557. $\quad$ E-mail: marta.furlan@yahoo.com.br

${ }^{3}$ Pós doutor em Educação pela Universidade Federal de São Carlos (UFSC). Doutor em Teologia pela Universidade de Ciências Humanas de Strasbourg, França. Lattes: http://lattes.cnpq.br/3355200763911829. ORCID:

http://orcid.org/0000-0001-5657-8651. E-mail: nilo.agostini@gmail.com
} 
feeding the splinters of hope that, according to Freire, will be fertilized by reliability in a lifecreating revolution.

Keywords: Education. Chronos. Remote Teaching.

\section{INTRODUÇÃO}

Na mitologia grega, Chronos é o deus do tempo e rei dos titãs, filho de Urano (céu estrelado) com Gaia (terra). Segundo os registros sobre os mitos feitos por Hesíodo em sua Teogonia, Chronos invejava o poder de seu pai, Urano, o governante do universo. Urano conquistou a inimizade de Gaia, mãe de Chronos, ao esconder os gigantes filhos de Gaia, Hecatônquiros e Ciclope, no Tártaro. Então, Gaia construiu uma harpe e convenceu Chronos e seus irmãos a usá-la para castrar Urano.

A pedido de sua mãe, Chronos se tornou senhor do céu, castrando o pai com um golpe de foice e jogando seus testículos no oceano. A partir de então, o mundo foi governado pela linhagem dos titãs, que, segundo Hesíodo, constituía a segunda geração divina. Foi durante o seu reinado que a humanidade (recém-nascida) viveu a sua era dourada; casou-se com a irmã Réia e governou durante a Idade Dourada da mitologia. Seu poder perdurou até ser derrubado pelos filhos Zeus, Poseidon e Hades.

De acordo com a mitologia, Chronos temia uma profecia segundo a qual seria tirado do poder por um de seus filhos. De temperamento violento e negativo, passou a matar e devorar todos os filhos gerados com Réia. Porém, a mãe conseguiu salvar um deles, Zeus, escondendo-o numa caverna da ilha de Creta. Para enganá-lo, Réia deu-lhe uma pedra embrulhada num pano que ele comeu sem perceber.

Ao crescer, Zeus libertou os titãs e com a ajuda deles fez Chronos vomitar os irmãos (Hades, Hera, Héstia, Poseidon e Deméter). Zeus, com a ajuda dos irmãos e dos titãs, expulsou-o do Olimpo e governou como o rei dos deuses gregos. Como tinha derrotado o pai Chronos, que simbolizava o tempo, Zeus tornou-se imortal, poder estendido também aos irmãos. Então, Zeus tornou-se senhor do céu e divindade suprema da terceira geração de deuses da mitologia grega, ao banir os titãs para o Tártaro e afastar o pai do trono. Segundo as palavras de Homero, Zeus prendeu-o com correntes no mundo subterrâneo, onde foi encontrado, após dez anos de luta encarniçada, pelos seus irmãos, os titãs, que tinham pensado poder reconquistar o poder de Zeus e dos deuses do monte Olimpo. 
Em algumas variantes do mito, Chronos e os titãs são alcançados pela misericórdia de Zeus, libertados do Tártaro e cada qual retoma a sua função cosmológica no universo. Com a permissão do filho, Hades, Chronos torna-se o governante dos Campos Elísios (que se localiza no mundo inferior), lugar de descanso para os mortos bem-aventurados. Segundo a Eneida de Virgílio, Chronos, após ser derrotado por Zeus, se refugiou no Lácio, onde se tornou rei e legislador.

Mediante as considerações introdutórias, há o seguinte questionamento: O que significa compreender a educação remota em tempos de pandemia da Covid-19 a partir dessa metáfora da maldição de Chronos na mitologia? Por meio deste ensaio teórico, objetiva-se desenvolver uma releitura reflexiva desses temas que se inter-relacionam, cujo fio condutor será uma reinterpretação adorniana da educação contra a barbárie, ou parafraseando, Adorno, da Educação após Auschwtiz, por Educação após pandemia como contraponto de um tempo de desesperança. Isto nos leva a abordar igualmente o kairós que, em Benjamin, suscita a força messiânica do ser humano na luta pela libertação, alimentando os estilhaços de esperança que, segundo Freire, serão adubados pela confiabilidade numa revolução criadora de vida.

Recorreu-se ao mito de Chronos como deus do tempo por pensar a questão temporal, sobretudo, quando visto em seu aspecto destrutivo, o tempo se constitui inexpugnável que rege os destinos e que tudo pode devorar. $\mathrm{Na}$ atual pandemia, o isolamento social nos colocou diante do impasse e do enfrentamento em relação ao tempo de vida, de morte, da doença, da dor. Basta perceber os noticiários e boletins de saúde sobre o tempo de incubação do vírus no nosso corpo. Buscou-se identificar em quanto tempo e com que rapidez ele se espalha e contamina, após quanto tempo aparecem os sintomas e o tempo depois em que se manifestam as sequelas ou, senão, a morte como o fim do tempo da vida. Também e não menos preocupante é o tempo do trabalho remoto, tempos do home office. A maioria das pessoas estão em casa aparentemente com muito tempo e, ao mesmo tempo, com pouco tempo. Isso leva a entender sobre um tempo de paradoxos do tempo.

O tempo nos devora, nos consome às voltas da maldição do tempo de Chronos, desse tempo que, além de nos devorar, a tudo devora para além de nós. O filósofo e professor Ricardo Timm de Souza, no seu livro "O tempo e a máquina do tempo", indica que a "humanidade tem concebido normalmente o tempo como uma cadeia infinita de acontecimentos intimamente imbricados, sem nenhum espaço para a indeterminação" (SOUZA, 1998, p. 136). O tempo se confunde com os movimentos regulares da esfera celeste, destacando assim, o tempo do relógio, da cronologia. O tempo pensado em seus aspectos cronológicos cíclicos, de tempos e tempos 
continuamente acontecendo. Desse modo, a pandemia veio modificar essa lógica ou, pelo menos, nos provocar a repensar o nosso tempo.

Nesse contexto de pandemia, em certo aspecto, o tempo desacelerou, as cidades pararam, o tempo da educação se modificou e vem se metamorfoseando. Em decorrência desse acontecimento, é mister destacar dois aspectos em relação a essa mudança na percepção do tempo durante a atual pandemia. Um primeiro aspecto consiste em pensar essa perceptibilidade do tempo na forma subjetiva no âmbito do capitalismo avançado. Uma pergunta de saída a ser feita: O que é o tempo? Como pensamos o tempo na sociedade capitalista? Diretamente, não há uma resposta objetiva única ou um conceito em específico que dê conta de responder o assunto. Porém, é indiscutível pensar que o respectivo tema cruze as formas subjetivas de percepção do tempo de diversas maneiras, circunstâncias e entendimentos.

Nesses termos, refletir esse tema a partir de alguns aforismas das Minima Moralia: reflexões a partir da vida danificada do filósofo Adorno; servem como metáfora para pensar a relação subjetiva do tempo no capitalismo e o que se pode chamar da grande máquina do tempo (SOUZA, 1998). No estado do capitalismo monopolista, radicalizado nos monopólios da especulação do capital financeiro internacional, em que a indústria cultural aumentou ainda mais seu poder, o capitalismo faz com que os sujeitos, que continuam sendo apêndices da maquinaria do tempo tecnológico, se tornem cada vez mais parecidos com ela. Esses e outros temas abordados por Adorno apontam a aguda situação do sujeito contemporâneo, cercados pela lógica do imediatismo, do instantâneo e do superficial.

No mundo do capital, a vida adquire um caráter pálido, prejudicado ou, como afirma o próprio Adorno:

\footnotetext{
Aquilo que "vida" significava outrora para os filósofos passou a fazer parte da esfera privada e, mais tarde ainda, da esfera do mero consumo, que o processo de produção material arrasta consigo como um apêndice sem autonomia e sem substância própria. Quem quiser saber a verdade acerca da vida imediata tem que investigar sua configuração alienada, investigar os poderes objetivos que determinam a existência individual no mais recôndito dela. (ADORNO, 1993, p. 7).
}

A configuração alienada que a vida assume contemporaneamente fortifica a compreensão de que a racionalidade instrumental está enraizada nos recônditos espaços da vida humana, ocultando-se naquilo que parece ser dela, ou seja, penetrando-a e contaminando-a de tal forma que ela se encontra danificada no sentido da alienação do indivíduo. Os argumentos se convertem em algo que mostra a modelagem de uma subjetividade moldada e absorvida pela totalidade social capitalista. 
A ideia de uma vida alienada e danificada aparece para Adorno como o resultado do condicionamento do sujeito absorvido pela totalidade social burguesa. O que caracterizaria a vida dos indivíduos como coerção funcional, demonstra uma circunstância em que o membro particular da espécie humana se vê adestrado por uma rede funcional do sistema em que está inserido. O momento mais elevado desse poder sobre a vida humana é revelado pelo poder adquirido pelo dinheiro, pela propriedade.

Na sociedade regida pela lógica da produção e do consumo, a realização do trabalho é sua objetificação, ou seja, o sujeito transformador e a natureza a ser transformada são objetificados. É nesse sentido que a realização do trabalho é a negação do ser humano, tanto em sua universalidade quanto em sua singularidade. No trabalho, não é dele o telos da atividade, não é dele a matéria trabalhada e nem o produto. Essa inversão refere-se à relação com o produto, que, segundo Marx, torna-se um "objeto alheio que exerce domínio sobre o homem”; refere-se também a uma relação com a própria atividade. Portanto, a alienação é a expressão de uma inversão que ocorre no relacionamento do ser humano com ele mesmo. As razões da permanência da alienação são numerosas e podem ser procuradas no esfacelamento dos indivíduos no próprio capitalismo.

No texto Capitalismo tardio on sociedade industrial? (1994), Adorno considera que no "Capitalismo tardio" as relações de produção se revelam mais elásticas do que Marx imaginara. É sob esta perspectiva que os mecanismos permitem a permanência extemporânea da ideologia da produtividade e alienação máxima dos indivíduos. Alienação é esse fenômeno que viabiliza a permanência do capitalismo, num contexto em que na sua irracionalidade do tempo - algo que se demonstra na desproporção, na superfluidade e no desperdício - suas contradições tornam-se expostas.

A inexistência de uma consciência de classe, o declínio da participação do trabalho vivo nas atividades industriais "só de um modo muito forçado e arbitrário são ainda interpretáveis sem utilizar o conceito-chave 'capitalismo'. A dominação sobre seres humanos continua a ser exercida através do processo econômico" (ADORNO, 1994, p. 67). O resultado desse triunfo da lógica da produção e do consumo é a criação de uma aparência "de que o [...] o ideal seria a plena ocupação e não o interesse em libertar-se do trabalho heterônomo" (ADORNO, 1994, p. 69).

Assim, uma vida danificada é aquela que se define a partir de uma determinada relação entre a vida e a produção, uma relação que é de sujeição da vida ao processo produtivo. A despeito de todo o progresso da técnica e do crescimento da produção, a atual sociedade revela aspectos estáticos. Eles fazem parte das relações de produção: aqui não há progresso desde que o capitalismo existe. Mas, em que sentido estas relações de produção se estagnaram, a despeito de 
todo o progresso das forças produtivas, mesmo com todo o avanço das tecnologias novas? Essa questão remete ao descolamento entre o interesse objetivo e a espontaneidade subjetiva. A socialização radical, no dizer de Adorno, "paralisa a simples capacidade de imaginar concretamente o mundo de um modo diverso de como ele dominadoramente se apresenta àqueles pelos quais ele é construído...” (ADORNO, 1994, p. 70).

Um segundo aspecto a ser pensado tem a ver com a educação em tempos de pandemia. Um problema a ser enfrentado para se falar em educação em tempos pandêmicos, consiste na recusa, em tratar a questão de uma forma prosaica, simplista e anêmica, ou seja, desprovida de "sangue, suor e lágrimas" na corrida contra o tempo. Nesta sociedade do tempo cronológico, movidos pela máxima, que virou dito popular "tempo é dinheiro". A essência educativa nesses tempos pandêmicos, se é que poderíamos dizer desse modo, não está "atrás" somente da aparência didático-pedagógica, se usamos ou não as tecnologias digitais, se ajudam ou atrapalham, entre outras falsas polêmicas. Mas, está vinculada à reflexão da aparência acerca do modo educativo que se articula na remissão do seu duplo caráter dialético diante das próprias consequências da pandemia, isto é, daquilo que Adorno chamou de adaptação e resistência na sua perspectiva da teoria crítica.

Adorno, ao contrário de um resignado pessimismo, não hesita em considerar que enquanto não se modificarem as condições objetivas haverá sempre uma lacuna entre as pretensões formativas e suas realizações. A pandemia exacerbou as desigualdades sociais e educacionais. Disto resulta que a educação durante a pandemia descortinou o grande abismo social que enfrentamos no Brasil, que estava quase que naturalizado e compreendido, em alguns espaços, como algo que já teríamos tudo resolvido, que só restava alguns "atrasados" e "descomprometidos". Por surpresa de alguns ou de muitos, descobrimos que temos um déficit educacional e formativo assustador.

Embora entendamos que tenha que se levar a cabo uma proposta desestruturadora da totalidade social vigente. Isso não significa superestimá-la, mas corresponde à necessidade de compreender a educação, a própria educação em seu papel de resistência e crítica. Disso depende a compreensão dos aspectos da tensão dialética do conceito educativo, em seus fatores que estão atualmente se constituindo em inúmeros mecanismos deformativos. Adorno sempre preferiu falar a partir da negatividade do conceito inserido em momentos aparentemente insignificantes da realidade concreta, como sendo uma recusa ao fundamento último do conceito.

$\mathrm{Na}$ impossibilidade de saber o que Adorno diria, sistematicamente, sobre a condição humana nesse nosso tempo de pandemia, a questão é compreender alguns "rastros" e "vestígios" encontrados em sua obra sobre a condição da vida e da educação. Nisso consiste, com o autor, 
considerar que ambas se encontram danificadas no contexto atual, como vimos anteriormente. Sobretudo, se levar em consideração os fatos históricos, que parecem confirmar esta ideia. Nesse sentido, pretende-se apresentar aqui alguns vestígios da crítica imanente da formação educativa, que indique não as sobras de uma totalidade que não se admite fragmentada, mas como aquilo que se apresenta no prisma do pensamento moderno. Rastro e vestígio educativos, onde ainda é possível ler algum sentido pela via negativa (TIBURI, 2005, p. 223).

A pergunta educativa trata-se da expressão do sentido da própria relação pedagógica. Se existe uma maioridade educativa, ela se encontra em questões fundamentais do existir pedagógico: o que vou ensinar e aprender? Para que e como vou aprender? E a mais fundamental de todas: Por que vou aprender? Educar, desse modo, significaria constituir relações não com uma totalidade amorfa e impessoal, mas recriar o sentido das partes corroídas pelo pensamento que se fez totalizante e unificado. No atual momento as perguntas se direcionam para a educação remota em tempos de pandemia. Será que vamos ensinar nesse tempo? O que vamos aprender? Como vamos aprender nessa panaceia da virtualidade irrefletida?

Na coletânea Erřiebung zur Mündigkeit, na tradução brasileira Educação e emancipação, foi um projeto de Adorno desenvolvido com Helmut Becker e Gerd Kadelbach, produzidas em parceria com a Divisão de Educação e Cultura do Estado de Hessen cuja série "Questões educacionais da atualidade" foram realizadas no período de 1959 a 1969, encontramos algumas "intuições" provocativas. Os escritos assinalam a coerência epistemológica da teoria crítica no desvendamento do processo histórico de produção social com a dominação capitalista. Ao mesmo tempo, apontam uma dimensão formativa a ser desenvolvida, principalmente, pela educação formal. Assim, as questões que se colocam são: como é possível dialogar com Adorno para compreender a tensão presente entre as necessidades para uma educação formativa adequada e as condições para efetivá-la em tempos de pandemia? Como a educação pode contribuir para nos livrar da maldição de Chronos em tempos de educação remota?

É possível pensar tais questões e alguns elementos presentes na tensão existente entre as aspirações e os desafios que se colocam para a educação de hoje. Adorno reconhece haver uma crescente preocupação com a extensão da educação para todos os níveis a um maior número de pessoas. O que não deixaria de isso ter importância, mas sendo necessário também perguntar acerca dos conteúdos, isto é, “do que é e do para que é a educação?” (ADORNO, 1995, p.139).

Adorno sustenta que esta pergunta não consistiria em perguntar apenas "para que fins a educação ainda é necessária?”, o que colocaria numa relação de subserviência a lógica dominante de resultados. Mas, valeria perguntar "para onde a educação deve conduzir?" (ADORNO, 1995, p. 139). Isto significa que esta orientação já não é mais evidente, pois não pode ser derivada da 
tendência objetiva imediata, nem tampouco de uma totalidade cultural como o fora ao longo da tradição metafísica. Adorno reconhece que seria comum o ressurgimento da exigência de restauração de "modelos ideais" para orientar as ações dos indivíduos.

No entanto, estes modelos constituem uma forma de controle, um momento autoritário, imposto a partir do exterior (ADORNO, 1995, p. 141), sem que com isso estejamos submetidos a ele. Não é à toa que Adorno, ao discutir o problema da formação na Alemanha, reflete as perspectivas de constituição de uma educação para a maioridade, isto é, para autonomia. O que isso significa? Significa que apesar da necessidade que temos de cumprir as regulamentações e os dispositivos legais do Estado, ainda assim, é possível constituir processos de autodeterminação e autonomia regidos nos embates e discussões no interior de cada unidade formativa e, também, com a comunidade.

A necessidade de uma educação para maioridade tem uma relação com a aposta de que a atividade crítica e reflexiva pode ser estendida a todas as pessoas. Esta ideia de educação, expõe a necessidade de decifrar as condições e os determinantes históricos que causam o modo ao qual os indivíduos estão submetidos. Por isso, o empenho adorniano volta-se, sobretudo, para a difusão de uma educação política, isto é, de uma formação conscientizadora das contradições sociais que destaque os limites da própria sociedade.

Adorno, ao explicitar o papel político da educação, aponta com toda força para uma "educação para a contradição e resistência". Sobretudo, para se contrapor às formas de degeneração educativa. Tal degeneração é produto de sua carência reflexiva, pois, no entender adorniano, educar significa levar a sério o tempo necessário para a construção de sentido que se dá na relação pedagógica. Esse tempo é muito mais do que uma sequência cronológica da maldição de Chronos, como no caso da educação formal, muitas vezes é conduzida (séries, ciclos, níveis etc.).

A formação não se resolve numa fórmula qualquer, mas depende da forma deliberada da relação entre os envolvidos no processo educativo. E isto é uma relação que implica um sentido tríplice entre o ético, estético e político. A educação é relação com o outro, se não for, cairá no solipsismo (caráter solitário) e no imediatismo, pelo qual problemas são resolvidos antes mesmo de surgirem. Respostas são dadas a perguntas que não mais são feitas. E perguntas ficam sem respostas.

Adorno não discute o conceito de maioridade como mera finalidade pedagógica. Sua indicação está na necessidade de liberação dos indivíduos do processo de dominação técnica da consciência. Inverter a educação de sua lógica meramente técnica pressupõe dar lugar para aquilo 
que fica à sombra da racionalidade instrumental. É tornar a educação cúmplice das experiências vitais da existência humana.

Portanto, a exigência de uma educação para maioridade parece ser necessária, de modo particular, numa sociedade em que os processos pedagógicos são submetidos aos mecanismos empresariais de organização escolar. Para Adorno, os fins da educação, no sentido de para onde ela deva conduzir, remete-nos aos conteúdos sociais da formação cultural (Bildung). Trata-se, portanto, da necessidade de reflexão sobre os processos histórico-culturais a fim de transcendêlos da condição em que estão colocados.

Adorno, mesmo não sendo um teórico da educação, oferece em suas reflexões condições fundamentais para uma educação autorreflexiva dos indivíduos. Pois, para ele, a "educação tem sentido unicamente como educação dirigida a uma auto-reflexão crítica" (ADORNO, 1995, p. 121). Isso significa que, mesmo inseridos nos processos de (de)formação do nosso tempo, é adequado buscar um arcabouço substancial de resistência para as relações danificadas.

\section{ENTRE O VAZIO DO CHRONOS E O TEMPO PLENO DO KAIRÓS}

Ao recorrer ao mito de Chronos, deus do tempo, desvela-se o aspecto destruidor do tempo que rege a vida humana e que tudo pode devorar. Cabe aqui uma reflexão deste Chronos, vazio, linear e conformista, próprio de uma vida administrada, contrapondo-o ao tempo pleno do kairós, pela ótica de Walter Benjamin, com alguns aportes de Paulo Freire.

Como já explicitado, o contexto atual, especialmente em meio à atual pandemia, é revelador de uma sociedade administrada sob o influxo do capitalismo que controla o Chronos, gerador de uma vida alienada, já danificada, sobretudo quando o sujeito é absorvido pela totalidade burguesa que invade o social e condiciona as pessoas, tornadas indivíduos isolados sem a relação altruísta com os outros. A força de transformação mostra-se aparentemente frágil, seja diante dos que já tombaram como vítimas da história seja diante das carruagens que insistem em passar por sobre os corpos dos que foram abatidos no passado e nos dias de hoje. Por um lado, o individualismo parece ganhar terreno nesta sociedade administrada, fragilizando a cooperação, a convivência, a noção de bem comum e da dignidade das pessoas; por outro lado, há uma frágil força em curso, que Benjamin (2016, p. 242, tese 2) nomeia de "messiânica" que faz irromper o "Kairós"; esta aspira por uma comunidade livre, almeja construir um futuro novo, alimenta uma visão crítica da história, bem como desfere uma crítica contundente ao progresso atual.

O Chronos representa a linearidade cronológica do tempo, alimentando um historicismo em favor dos vencedores; destrói a memória dos vencidos, conduz ao conformismo e controla as 
energias latentes na história, neutralizando e esterilizando as imagens do passado; impede qualquer irrupção revolucionária que leve a mudanças reais na sociedade. Faz-se necessário romper com o continuum desta história, alimentada pelo progresso tão propalado da modernidade industrial que, embalada pelo capitalismo, impõe uma visão linear, adestradora e controladora, forjando uma civilização sem memória e sem esperança. Para esta modernidade, basta treinar para a repetição, num ajuste dos indivíduos ao sistema que perpetua a opressão, aumenta o número dos vencidos, cujos corpos servem como chão batido por onde passa o cortejo triunfal dos vencedores. É preciso romper com a imposição do Chronos e instaurar o Kairós.

Romper com o chronos para que o tempo pleno do kairós se instaure é
interromper a catástrofe presente, sabendo ler os sinais do "tempo de agora",
com sua temporalidade messiânica, superando o vazio temporal das ideologias
do progresso. Irrompe o tempo qualitativo, deixando para trás o tempo vazio.
É preciso captar o momento oportuno para interromper a continuidade da
"submissão servil a um aparelho incontrolável", produzida por políticos, cuja
"obtusa fé no progresso" impõe às massas para manipulá-las e controlá-las,
segundo Benjamin (2016) na tese 10 (AGOSTINI, 2019, p. 103).

Ao apresentar o Kairós, como noção de fundo, Benjamin (1977, p. 77) remete para a "totalidade" da pessoa, numa restitutio in integrum para, em seguida, sublinhar a importância da comunidade e alimentar a ideia de uma redenção, de uma libertação, graças a uma vida ao mesmo tempo espiritual e criadora que se orienta em direção à renovação, como força de irrupção transformadora. Daí advém a esperança que inclui a política, ambas orientadas a "salvar a memória dos esquecidos" da história, dos "vencidos" na sociedade, sendo necessário fazer-lhes justiça. Nessa obra transformadora e reparadora, não há passividade; é tarefa concreta, é consciência ativa, é messianismo encharcado pela história, evocando a "frágil força messiânica" da qual cada um de nós é participante, convocados a exercê-la em vista de uma "humanidade restituída, salva, restabelecida" (LÖWY, 2005, p. 55, 56, nota 31). Mesmo frágil, estamos aqui diante de uma "força concreta", no "palco da história, onde a justiça desfere a sua sentença final" (CANTINHO, 2011, p. 188).

Benjamin (2016, p. 249), de forma perspicaz, nos alerta das garras do conformismo de uma história linear, em meio à "arena comandada pela classe dominante", e nos convida a interromper a catástrofe presente, salvando a herança dos oprimidos, para no "tempo de agora" (Jetrtzeit) instaurar o tempo pleno do Kairós. Este tempo difere do Chronos, que é o tempo formal, da mera repetição, homogêneo e vazio, próprio da visão linear e acomodatícia da história. Kronos remete para a capacidade de lançar-se, com astúcia, em busca do tempo histórico pleno, para encerrar a barbárie e superar a passividade; trata-se do processo no qual o potencial de emancipação é aflorado e resgatado, como resposta astuta, engenhosa e rápida, "capaz de captar 
o momento oportuno do engajamento de uma determinada ação" (MISSAC, 1998, p. 11); é saber identificar o tempo favorável que, qual faísca, faz irromper o tempo da redenção, sabendo "transformar o mau augúrio em presságio favorável".

Tempo de agora (Jetztžeit) e Kairós são equivalentes na abordagem do tempo e da história, o que faz Benjamin (2016, p. 249) afirmar que "a história é objeto de uma construção, cujo lugar não é formado pelo tempo homogêneo e vazio, mas preenchido do 'tempo de agora"'. No tempo de agora, ascende-se a centelha da esperança, revela-se a redenção, qual Kairós, contrapondo-se ao historicismo e à ideia de progresso linear para o qual conta uma concepção apenas quantitativa e acumulativa, por isso homogêneo e vazio. "Brilha a centelha messiânica", quais "estilhaços do messiânico" (LÖWY, 2005, p. 140) que irrompem como momentos instantâneos nas frestas da história e prefiguram a libertação dando o sinal de alerta ante o horror e as atrocidades quer do passado quer do presente.

Freire (2014b, p. 76), por sua vez, é muito atual quando afirma a necessidade de pronunciar o mundo sem que caiamos na tentação da "propaganda, do dirigismo e da manipulação"; o empenho, na via freiriana, é pela humanização, fruto da ação libertadora que requer "um profundo amor ao mundo e aos homens" (p. 110); trata-se de remover os obstáculos à humanização, buscando a transformação do mundo, em vista de uma "crescente libertação dos homens" (p. 241). Como se trata de um "caminho de amor pela vida" (p. 76), contrasta com a opressão, que é necrófila, pelo seu "amor à morte" (p. 90). Alimentado pela confiança no povo e pela esperança sempre presente, Freire (2014b, p. 110) aposta no "ato de criação" como capacidade dos "sujeitos dialógicos" que edificam o "mundo para a libertação".

Freire (2014a, p. 101) ainda sublinha a necessidade de uma "transformação criadora" como própria da "vocação ontológica e histórica de humaniza-se". Isto implica, para ele, engajarse no "caminho do amor à vida" (p. 76), numa "revolução biófila" que é "criadora de vida" (p. 233). Tem-se, assim, uma responsabilidade ante a opressão que espalha a "morte em vida" (FREIRE, 2014b, p. 233), sendo o objetivo fundamental "lutar com o povo pela recuperação da humanidade roubada", instaurando uma práxis, ou seja, "reflexão e ação dos homens sobre o mundo para transformá-lo” (p. 52).

Benjamin (2002, p. 39) declara-se "defensor da vida mais elevada", no sentido de preservar o "espírito criador", não cedendo à tendência burguesa de apenas ajustar-se "a reboque" ou de maneira "mecanicista" à sociedade liberal, sendo um dos traços desta a "tendência burguesa, indisciplinada e mesquinha" que se submete fácil a uma visão acrítica e paralisante (p. 34); trata-se de salvaguardar "uma comunidade de criadores que atua através do amor" (p. 44) como forma de vida; isto requer uma "reconstrução integral" (p. 39), "conferindo 
unidade, a partir da vida espiritual". Para isso, faz-se necessário "escovar a história a contrapelo", o que, para Benjamin (2016, p. 245), é uma tarefa a realizar a partir dos vencidos, vítimas da barbárie dos vencedores, vítimas de um progresso saído da modernidade, cujas "ruínas crescem até o céu" (tese 9).

\section{CONCLUSÃO}

Ao retomar o objetivo geral desse ensaio, evidencia-se a intencionalidade da discussão e reflexão sobre a atualidade e a persistência dos diversos modos de submissão da educação aos limites da maldição de Chronos. E o que isso significou? Significou compreender que a formação dos indivíduos, nesse particular, a educação em tempos pandêmicos, tornou-se intrinsecamente limitada. A partir desse ponto, percebeu-se a articulação de algumas formas de desencantamento da educação, colocando em evidência a crítica dialética e a expressividade estética dela em detrimento de uma racionalidade instrumental que, mesmo na condição de medida emergencial, tem se configurado como fins e não como meio, ou seja, limita-se enquanto possível saída do caos que, de certa forma gera novos caos, como é o caso do fortalecimento das desigualdades sociais via tecnologia.

O encaminhamento notório no texto é da potência da resistência ante a maldição do tempo cronológico que nos faz vítimas para o sacrifício do deus do tempo. Não precisamos fazer como Zeus, que matou seu pai Chronos, pelo desejo e ambição de se tornar tão poderoso quanto ele. Mas é crucial enfrentar a maldição, não negando-o ou relegando-a a segundo plano.

O desafio consiste em reconhecer que ela está aí e que é preciso resistí-la, ressignificá-la, talvez não com muita sofisticação tecnológica, mas pelo prazer do encontro, mesmo que virtual como tem acontecido neste contexto atual. Que não seja na mera satisfação das horas e do tempo corrido, das muitas lives, que em quantidade tem muitas e envolvendo temáticas para todos os gostos, entretanto, entretanto é necessário que haja o aproveitamento desses momentos para dignidade das nossas vidas e dos nossos alunos, e porque não dizer, da própria sociedade.

Enfim, reservar um tempo para nos proteger, além do vírus, mas também daqueles que querem capturar nosso tempo para seus interesses espúrios! Eis o desafio dos tempos de pandemia. 


\section{REFERÊNCIAS}

ADORNO, T. W. Educação e Emancipação. Trad. Wolfang Leo Maar. 1. ed. Rio de Janeiro: Paz e Terra, 1995.

ADORNO, T. W. Capitalismo tardio ou sociedade industrial. In: COHN, G. (Org.). Theodor W. Adorno. São Paulo: Ática, 1994. p. 62-75.

ADORNO, T. W. Minima moralia. Trad. Luiz Eduardo Bicca. 2. ed. São Paulo: Ática, 1993.TIBURI, Márcia. Metamorfose do conceito: ética e dialética negativa em Theodor Adorno. Porto Alegre: Editora da UFRGS, 2005.

AGOSTINI, N. Os desafios da educação a partir de Paulo Freire e Walter Benjamin. Petrópolis: Vozes, 2019.

BENJAMIN, W. Magia e técnica, arte e política. Ensaios sobre literatura e história da cultura.

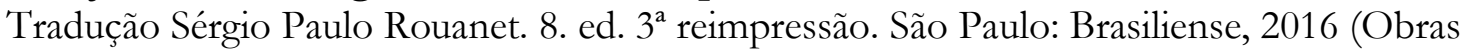
escolhidas 1).

BENJAMIN, W. Reflexões sobre a criança, o brinquedo e a educação. Tradução Marcus Vinicius Mazzari. São Paulo: Editora 34, Duas Cidades, 2002.

BENJAMIN, A.; OSBORNE, P. (Org.). A filosofia de Walter Benjamin. Rio de Janeiro: Jorge Zahar, 1997.

CANTINHO, M. J. Walter Benjamin e a história messiânica contra a visão histórica do progresso. Philosophica, Lisboa, v. 1, n. 37, p. 177-195, 2011.

FREIRE, P. Educação como prática da liberdade. $36^{a}$ edição. Rio de Janeiro, São Paulo: Paz e Terra, 2014a.

FREIRE, P. Pedagogia do oprimido. $57^{\mathrm{a}}$ edição. Rio de Janeiro, São Paulo: Paz e Terra, 2014b.

LÖWY, M. Walter Benjamin: aviso de incêndio: Uma leitura das teses "Sobre o conceito de história". Tradução Wanda Nogueira Caldeira Brant, Jeanne Marie Gagnebin, Marcos Lutz Müller. São Paulo: Boitempo, 2005.

MISSAC, P. Passagem de Walter Benjamin. Tradução Lilian Escorel. São Paulo: Iluminuras, 1998.

SANTOS, R. T. O tempo e a máquina do tempo. Estudos de Filosofia e Pós-modernidade. EDIPUCRS, Rio Grande do Sul, 1998. 